\title{
Examining Perceptions of Rapid Population Growth in North and South Gondar Zones, Northwest Ethiopia
}

\author{
Getu Degu Alene and Alemayehu Worku \\ School of Public Health, Faculty of Medicine, Addis Ababa University, Addis Ababa, Ethiopia
}

\begin{abstract}
Ethiopia is one of the most populous countries in Africa and ranks second only to Nigeria. Rapid population growth has hampered the country's development, making the eradication of extreme poverty and hunger difficult. This study which had two components-quantitative and qualitative-was aimed at exploring the perceptions of women and other social groups on the prevailing population pressures. The quantitative study involved 3,512 women aged 15-49 years. The qualitative study consisted of five focus-group discussions and six key-informant interviews. Over $90 \%$ of women $(n=3,512)$ who participated in the quantitative study and nearly all the focus-group discussants and interviewees $(n=39)$ felt that something should be done to keep the population from growing too fast. Most (over 90\%) participants approved of the Government passing a law regarding the maximum number of children that a couple should have. It is, therefore, timely for the responsible bodies to exert maximum effort and commitment in responding to the emerging attitudes of the people by making the population problem a priority.
\end{abstract}

Key words: Cross-sectional studies; Perceptions; Population growth; Ethiopia

\section{INTRODUCTION}

The development challenges facing sub-Saharan Africa are made greater by rapid population growth and poor reproductive health. The impact of other investments in the region will be undermined unless governments move quickly to address these problems (1). Enabling people to have fewer children, if they want to, helps to stimulate development and reduce poverty in both individual households and societies. Smaller families have more to invest in education and health of children. Rapid population growth contributes to environmental stress, uncontrolled urbanization, and rural and urban poverty (2).

Ethiopia, a federal republic, consists of nine regional states and two city administrations. Its population was projected to be 77.1 million in mid-2007 (ranks second only to Nigeria). However, according to the recent census, it was reported to be about 74 million in 2007. The regions are divided into

Correspondence and reprint requests should be addressed to:

Dr. Getu Degu Alene

School of Public Health

Faculty of Medicine

Addis Ababa University

Addis Ababa, Ethiopia

E-mail: adgetu123@yahoo.com zones, which are further divided into woredas (districts). The Amhara region where the present study was undertaken is one of the regional states of the country.

Women in sub-Saharan Africa continue to face a 1 in 16 chances of dying from pregnancy and childbirth when the risk for women in the industrialized world is 1 in 2,800 $(3,4)$. Maternal mortality (673 deaths per 100,000 livebirths) in Ethiopia is among the highest in the world (5). Similarly, according to the 2005 Ethiopian Demographic and Health Survey (EDHS), the infant mortality rate is also among the highest (77 deaths per 1,000 livebirths). The Amhara region was observed to have the highest infant mortality ( 94 deaths per 1,000 live births) among the 11 regions of the country. The available facts show that high fertility exposes women to high rates of maternal deaths. Many researchers have also reported unequivocally the association of an increased level of infant/child mortality with high fertility (6-8). Many studies have also shown the influences of other biological, behavioural, socioeconomic and cultural factors on high fertility $(5,9-11)$. Because of the negative influences of many direct and indirect factors, the status of women in Ethiopia is very low and has tremendously affected their participation in the labour force $(5,8,12)$. With all the prevailing back- 
ground characteristics of women in the Amhara region in particular and in Ethiopia in general, rapid population growth has complicated the situation, thereby making the eradication of extreme poverty and hunger very difficult. The country is caught in a vicious cycle: efforts to improve living standards and alleviate poverty are overwhelmed by the need to provide basic services and jobs for ever-growing numbers of people. With a population doubling time of less than 30 years, Ethiopia is at the crossroads of taking serious measures that will enable the country to escape the trap of abject poverty.

Ethiopia needs to break into the vicious cycle by reducing the excessive population growth to a level which is manageable and that can go in line with the economic development of the country (13). Accordingly, this investigation was aimed at exploring the perceptions of women and other social groups on the prevailing population pressure and at finding out their views towards the control of the present rate of population growth.

\section{MATERIALS AND METHODS}

The study had two parts. The first one was a quantitative study which involved women of reproductive age. The second part was a qualitative study which consisted of different social groups. The total population of North and South Gondar zones where the present study was carried out was estimated to be 5.6 million in mid-2008. About $28 \%$ of the Amhara people live in these zones.

\section{Quantitative study}

A cross-sectional survey aimed at exploring the perceptions and views of women on the prevailing population pressure was undertaken in North and South Gondar zones from mid-October to midDecember 2007. Women, aged $15-49$ years, who were permanent dwellers of the selected areas were eligible to be included. A woman was considered a permanent dweller if she had been living in the area for at least six months.

A multistage cluster-sampling method, which was stratified by urban and rural areas, was used for selecting the required study subjects. In total, 10 districts were covered. About two-thirds of the study subjects $(n=2,277)$ were from rural areas of the two zones. The remaining $(n=1,235)$ subjects were drawn from the two big urban centres (Gondar and Debre Tabour towns) and from the centres of the randomly-selected district (woreda) administrations. In this study, the centres of the two Gondar zones, which have the status of woreda administration, are called 'big towns' while the centres of the selected woredas are referred to as 'small towns'. Accordingly, five of the 20 rural woredas in North Gondar and three of the 10 rural woredas in South Gondar were randomly selected. The other two woredas (Gondar and Debre Tabour towns) were included to examine the perceptions of women residing in big towns (centres of zone administrations).

Although this particular investigation consisted of a number of outcome variables relating to population pressure, there appeared a difficulty in getting similar studies undertaken in the country which could be used as a basis for computing the required sample size. The study carried out by Ezra in the drought- and famine-prone areas of northern Ethiopia which had documented a proportion of $75.7 \%$ (opinions of respondents on the population size of their communities as too large) was a bit old (14). Therefore, it was decided to use a potential proportion of $50 \%$ to compute the sample size. This assumption usually gives the largest sample size and minimizes the amount of sampling error.

Accordingly, with the estimated proportion of $50 \%$, a $95 \%$ confidence interval, and a $2.5 \%$ margin of error, a sample size of 1,537 was initially computed. However, by taking into account the type of sampling method used, a design effect of 2 was employed. Finally, together with a 5\% contingency for non-response, a total sample size of 3,228 was proposed. On the other hand, there were 3,547 women aged $15-49$ years in the selected clusters and localities (kebeles), and data were collected from 3,512 of them, giving a response rate of $99 \%$.

Twenty health professionals (health officers, nurses, and environmental health technicians) who received a three-day intensive training with practical exercises collected the required data. Five health officers/sanitarians were assigned to supervise the data-collection process and the investigators handled the overall coordination. A standardized structured questionnaire with closed and open-ended questions was used for collecting the required data. Pre-testing of the questionnaire was carried out before undertaking the collection of main data, and some adjustments were made accordingly. In addition to the usual demographic and socioeconomic characteristics, variables pertaining to population pressure and the views of respondents towards alleviating the associated problems were incorporated.

\section{Qualitative study}

During the process of data analysis, there was an emerging phenomenon, which necessitated further inquiry into some issues not captured by the 
quantitative research methods. Therefore, to supplement and clarify some findings from the quantitative data, five focus-group discussions (FGDs) and six key-informant interviews were carried out in the same study areas and in the capital of the Amhara region (Bahar Dar). Three of the FGDs which consisted of 8, 7, and 6 participants (all married men) were conducted in Fogera, Dembia, and Dabat districts respectively. The other two FGDs were conducted with religious leaders. The six key-informant interviews were conducted with different individuals identified from various sources, including government institutions. The discussions were supported by flexible guidelines (a checklist). During the FGDs and key-informant interviews, the following major areas were considered: The perceptions of interviewees on the population pressure in their respective areas, the maximum number of children that a couple should have, and the positions of husbands and religious leaders on the use of contraceptives and preference for the sex of the first child. The process of data collection continued until more or less saturation or redundancy was reached. This actually took several circles of inquiry based on the leads that were generated during the discussions and interviews. Most discussions and interviews were recorded on tape. After the collection of data with a tape-recorder and by taking notes, the task of transcribing and translating into English was carried out. The usual principles that guide qualitative analysis were taken into account, and a sequence of interrelated steps (reading, coding, displaying data, data reduction, and interpreting) was employed while analyzing the qualitative data (15).

Ethical clearance was obtained from the School of Public Health and the Faculty of Medicine of Addis Ababa University. Written consent was obtained from the Amhara Regional State Health Bureau and responsible zone, Woreda and Kebele government organizations by explaining the objectives of the study. Verbal consent was obtained from each subject included in the quantitative and qualitative studies.

\section{RESULTS}

\section{Quantitative study}

Nearly $99 \%(n=3,512)$ of the 3,547 women responded to the questionnaire which consisted of several sections, including women's perceptions of population pressure. There were 15,308 individuals residing in the surveyed households $(\mathrm{n}=3,178)$, and this gave an average family size of 4.8 persons per household. The dependency ratio was about 100\%.
Of the 2,097 rural households included in the study, about $7 \%$ did not have any farmland. Of those households who reported as having some land were further examined; nearly $70 \%$ had less or equal to a hectare. The possession of farmland per head among these families would be much less than one-quarter of a hectare.

There were 612 livebirths in the year preceding the survey, making the crude birth rate 40 per 1,000 people. In total, 198 individuals died during the same year, and the crude death rate was 12.9 per 1,000 people. The natural growth rate was computed as $2.7 \%$. The crude death rates for the rural and urban areas were 13.3 and 12 per 1,000 people respectively. During the same year, the crude birth rates were 33.4 per 1,000 people in urban and 42.6 per 1,000 people in rural areas. The corresponding natural growth rates were, thus, calculated as $2.1 \%$ and $2.9 \%$ in urban and rural areas respectively. The total fertility rates were computed as 6.3 and 3.5 children per woman in rural and urban areas of the two Gondar zones respectively. The overall total fertility rate of the two Gondar zones was calculated as 5.3. The contraceptive prevalence rates (CPRs) among all women and married ones were also computed as $22 \%$ and $27.3 \%$ respectively.

Most (96\%) respondents reported that the number of people living within their respective surroundings had been increasing for years. They also expressed their feelings regarding the bad things that could take place following the rapid increase of population in a given country. Poverty, scarcity of farmland, famine, and drought were mentioned by over $93 \%$ of the study subjects as consequences of uncontrolled population growth (Table 1). Regarding the measures to be taken to alleviate the problem of population pressure, 3,195 (91\%) respondents felt that something should be done to keep the population from growing too fast. Over $92 \%$ $(n=2,948)$ of the 3,195 women proposed the use of birth-control methods as the main solution to the ever-increasing population growth (Table 2).

Table 2 shows that 3,232 (92\%) study women approved the passage of a law by the Government regarding the maximum number of children that a couple should have. Over three-quarters of the women who approved the passage of such a law were in favour of four or less children.

The experience of married women regarding the decisions made in the purchase and sale of major household properties was also investigated. Nearly $80 \%$ of the married women reported that they made decisions jointly with their husbands. Of the 


\begin{tabular}{|c|c|c|c|c|c|c|c|c|}
\hline \multirow{2}{*}{$\begin{array}{l}\text { Variable (percep- } \\
\text { tion) }\end{array}$} & \multicolumn{2}{|c|}{ Big towns } & \multicolumn{2}{|c|}{ Small towns } & \multicolumn{2}{|c|}{ Rural areas } & \multicolumn{2}{|l|}{ Total } \\
\hline & $\begin{array}{c}\text { Frequency } \\
(\mathrm{n}=756)\end{array}$ & $\%$ & $\begin{array}{c}\text { Frequency } \\
(\mathrm{n}=479)\end{array}$ & $\%$ & $\begin{array}{l}\text { Frequency } \\
(\mathrm{n}=2,277)\end{array}$ & $\%$ & $\begin{array}{l}\text { Frequency } \\
(\mathrm{n}=3,512)\end{array}$ & $\%$ \\
\hline \multicolumn{9}{|l|}{$\begin{array}{l}\text { Do you think the } \\
\text { number of people } \\
\text { who live in this } \\
\text { area is increasing? }\end{array}$} \\
\hline Yes & 719 & 95.1 & 463 & 96.7 & 2,189 & 96.1 & 3,371 & 96.0 \\
\hline $\begin{array}{l}\text { No } \\
\text { If increasing, how } \\
\text { rapidly do you } \\
\text { think it is increas- } \\
\text { ing? }(n=3,371)\end{array}$ & 37 & 4.9 & 16 & 3.3 & 88 & 3.9 & 141 & 4.0 \\
\hline Very rapidly & 397 & 55.2 & 225 & 48.6 & 1,036 & 47.3 & 1,658 & 49.2 \\
\hline Moderately & 322 & 44.8 & 238 & 51.4 & 1,153 & 52.7 & 1,713 & 50.8 \\
\hline \multicolumn{9}{|l|}{$\begin{array}{l}\text { Do you think that } \\
\text { your area has: }\end{array}$} \\
\hline Too many people & 675 & 89.3 & 440 & 91.9 & 2,141 & 94.0 & 3,256 & 92.7 \\
\hline $\begin{array}{l}\text { Just about the } \\
\text { right number }\end{array}$ & 81 & 10.7 & 39 & 8.1 & 136 & 6.0 & 256 & 7.3 \\
\hline \multicolumn{9}{|l|}{$\begin{array}{l}\text { What are some } \\
\text { bad things that } \\
\text { can happen if the } \\
\text { number of people } \\
\text { in a country in- } \\
\text { creases too fast? }\end{array}$} \\
\hline Poverty & 389 & 51.5 & 256 & 53.5 & 630 & 27.7 & 1,275 & 36.3 \\
\hline Land scarcity & 76 & 10.0 & 62 & 12.9 & 844 & 37.1 & 982 & 28.0 \\
\hline drought & 247 & 32.7 & 112 & 23.4 & 661 & 29.0 & 1,020 & 29.0 \\
\hline Migration & 27 & 3.6 & 16 & 3.3 & 69 & 3.0 & 112 & 3.2 \\
\hline Conflict/fighting & 10 & 1.3 & 9 & 1.9 & 42 & 1.8 & 61 & 1.7 \\
\hline Health problem & 7 & 0.9 & 24 & 5.0 & 31 & 1.4 & 62 & 1.8 \\
\hline
\end{tabular}

married women, $16.5 \%$ in big towns, $21.6 \%$ in small towns, and $61.1 \%$ in rural areas approved that the first marriage take place before the girl is aged 18 years (Table 3 ). The study subjects were also further probed whether they had given any thoughts to the question of how many children to have at the end of the day. Over two-thirds of these women had given no thought to the number of children they should have in their lifetime.

\section{Qualitative study}

\section{FGDs with farmers (married men)}

The participants of all the FGDs were aged 30-55 years. All the participants in the three FGDs confirmed the fact that the number of people is increasing over time while the area of farmland re- mains the same. Because of the rapid population growth, they feared that there could come a time when the people would not get a place to stand on if the present population growth persists. The next question was, therefore, to hear from them about the maximum number of children that a couple should have in their lifetime. Fifteen supported a maximum of three while five were in favour of four children. Only one suggested five children. Those who desired four or five children were relatively older. After the suggestion of each participant regarding the maximum number of children, the following questions were asked: "What do you think would be the solution? Do you accept if the Government passes a law regarding the maximum number of children? All approved the passage 


\begin{tabular}{|c|c|c|c|c|c|c|c|c|}
\hline \multirow{2}{*}{$\begin{array}{l}\text { Variable (proposed } \\
\text { measure) }\end{array}$} & \multicolumn{2}{|c|}{ Big towns } & \multicolumn{2}{|c|}{ Small towns } & \multicolumn{2}{|c|}{ Rural areas } & \multicolumn{2}{|c|}{ Total } \\
\hline & $\begin{array}{c}\text { Frequency } \\
(\mathrm{n}=756)\end{array}$ & $\%$ & $\begin{array}{l}\text { Frequency } \\
(\mathrm{n}=479)\end{array}$ & $\%$ & $\begin{array}{l}\text { Frequency } \\
(\mathrm{n}=2,277)\end{array}$ & $\%$ & $\begin{array}{l}\text { Frequency } \\
(\mathrm{n}=3,512)\end{array}$ & $\%$ \\
\hline \multicolumn{9}{|l|}{$\begin{array}{l}\text { Which do you think } \\
\text { would be better for } \\
\text { the population of a } \\
\text { country in the next } \\
10 \text { years? }\end{array}$} \\
\hline Gradually increasing & 12 & 1.6 & 14 & 2.9 & 68 & 3.0 & 94 & 2.7 \\
\hline $\begin{array}{l}\text { The same number } \\
\text { of people as now }\end{array}$ & 57 & 7.5 & 53 & 11.1 & 262 & 11.5 & 372 & 10.6 \\
\hline Rapidly decreasing & 139 & 18.4 & 81 & 16.9 & 426 & 18.7 & 646 & 18.4 \\
\hline $\begin{array}{l}\text { Gradually decreasing } \\
\text { Do you think } \\
\text { something should } \\
\text { be done to keep the } \\
\text { number of people } \\
\text { from growing too } \\
\text { fast? }\end{array}$ & 548 & 72.5 & 331 & 69.1 & 1,521 & 66.8 & 2,400 & 68.3 \\
\hline Yes & 728 & 96.3 & 448 & 93.5 & 2,019 & 88.7 & 3,195 & 91.0 \\
\hline No & 28 & 3.7 & 31 & 6.5 & 258 & 11.3 & 317 & 9.0 \\
\hline \multicolumn{9}{|l|}{$\begin{array}{l}\text { If yes, what do you } \\
\text { think should be } \\
\text { done? }(n=3,195)\end{array}$} \\
\hline Use of birth control & 687 & 94.4 & 415 & 92.6 & 1,846 & 91.4 & 2,948 & 92.3 \\
\hline $\begin{array}{l}\text { Teaching the peo- } \\
\text { ple/schooling }\end{array}$ & 35 & 4.8 & 21 & 4.7 & 95 & 4.7 & 151 & 4.7 \\
\hline $\begin{array}{l}\text { Stopping rapid } \\
\text { (frequent) births }\end{array}$ & 5 & 0.7 & 5 & 1.1 & 20 & 1.0 & 30 & 0.9 \\
\hline Others & 1 & 0.1 & 7 & 1.6 & 58 & 2.9 & 66 & 2.1 \\
\hline \multicolumn{9}{|l|}{$\begin{array}{l}\text { The Government } \\
\text { should pass a law } \\
\text { regarding the } \\
\text { maximum number } \\
\text { of children that a } \\
\text { couple should have }\end{array}$} \\
\hline Approve & 690 & 91.3 & 441 & 92.1 & 2,101 & 92.3 & 3,232 & 92.0 \\
\hline Disapprove & 66 & 8.7 & 38 & 7.9 & 176 & 7.7 & 280 & 8.0 \\
\hline \multicolumn{9}{|l|}{$\begin{array}{l}\text { If the respondent } \\
\text { approves, what is the } \\
\text { maximum number } \\
\text { of children that a } \\
\text { couple should have? } \\
(n=3,232)\end{array}$} \\
\hline $1-2$ & 227 & 32.9 & 110 & 25.0 & 123 & 5.9 & 460 & 14.2 \\
\hline $3-4$ & 442 & 64.1 & 292 & 66.2 & 1,246 & 59.3 & 1,980 & 61.3 \\
\hline$\geq 5$ & 21 & 3.0 & 39 & 8.8 & 732 & 34.8 & 792 & 24.5 \\
\hline
\end{tabular}




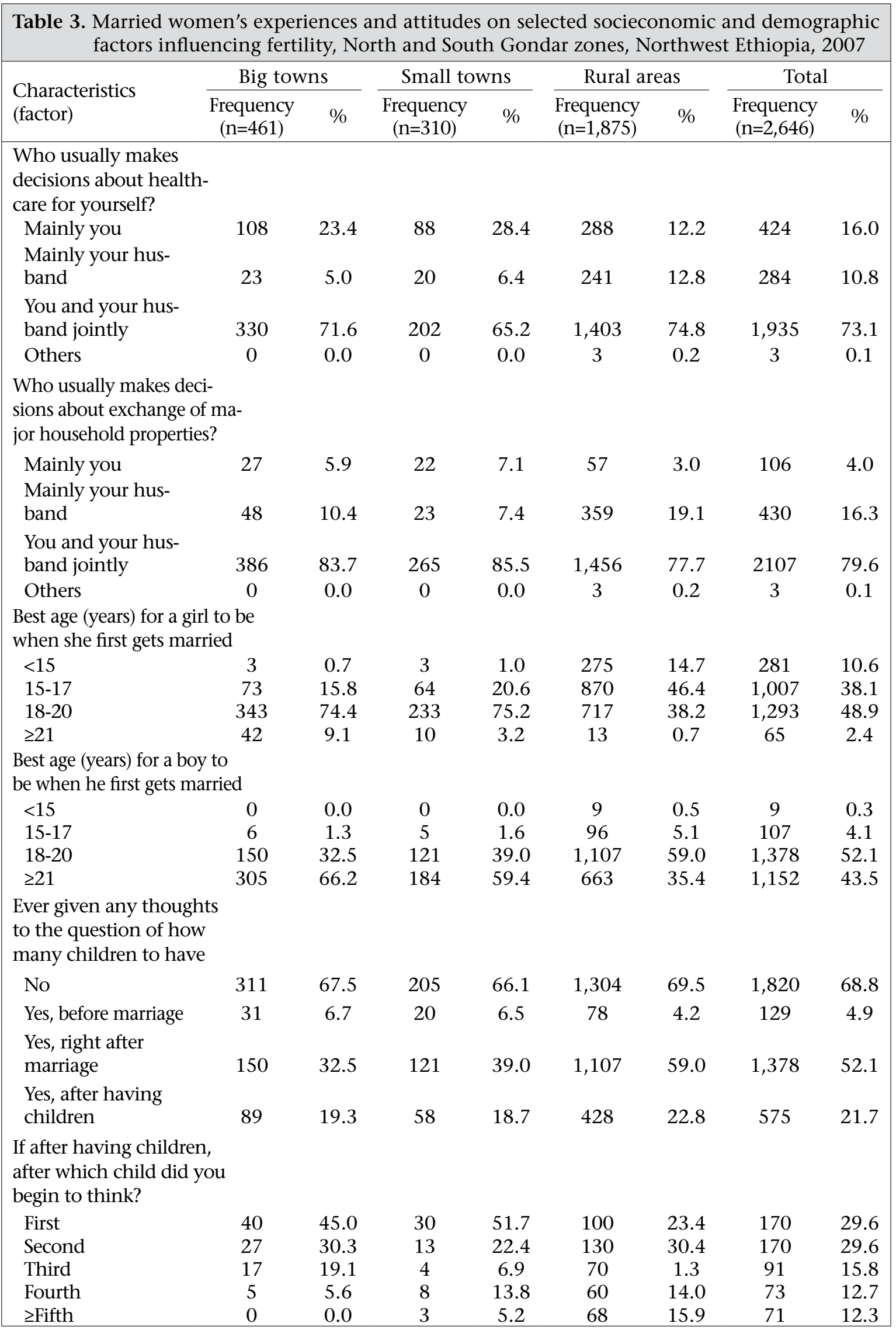


of a law without any hesitation. They were even worried about the future in which the present subsistence farming would be totally unable to hold up against the ever-increasing population. Most of them woefully said that they were running out of grassland where they could send their cows and oxen to graze.

Regarding preference for the sex of the first child, slightly over half of the farmers preferred a male child mainly for economic purposes. The remaining participants were in favour of female children for various reasons, including the achievements that girls make both at home and in the field.

Focus-group discussions and key-informant interviews carried out with religious leaders (Orthodox Christians and Muslims)

The FGD conducted with priests comprised six participants aged 28-68 years. All the participants of this FGD confirmed the fact that the number of people is increasing over time and mentioned the prevailing problems associated with the rapid growth rate. The next question asked to the priests was: what is the solution? All of them responded that the maximum number of births should be limited, and three were in favour of three children, followed by two and one children approved by two and one participants respectively. All the participants expressed their agreement to the Government passing a law regarding the maximum number of children that a couple should have throughout their lifetime.

Regarding the age at first marriage, most priests supported the minimum age set by the regional government which is 18 years. However, the oldest priest suggested 15 years. This proposal was backed by taking into account the age of the first female (i.e. Eve) who was believed to be 15 years when she was created.

On the other hand, the key-informant interview undertaken in Fogera (South Gondar) demonstrated a complete disagreement with the views of the priests in North Gondar. The priest interviewed who was aged 60 years could not deny the everincreasing population growth but was not comfortable to limit the maximum number of children and accept the mechanism to control the high fertility. He said, "No one knows the fate of any human creature; he could be a king or anything else. Therefore, it is forbidden to do anything to avoid the creation of humankind."

Another point was raised by the facilitator: "which one is preferable for a couple-prevention of con- ception or terminating pregnancy through abortion? The priest responded by saying that none of the options is recommended. The ones who do such things are divine law-breakers and are sinful. There is no need for man-made intervention. He extended his explanation by quoting from the Bible. God blessed Adam and Eve and said to them, "Be fruitful and increase in number; fill the earth and subdue it" (Genesis 1:28). If God likes, the priest said, "He can make the whole earth empty." On the other hand, the priest interviewed in Dabat district (North Gondar) who was aged 55 years supported to take a measure to inhibit uncontrolled population growth. He was in favour of three children and approved the passage of a law by the Government.

The other FGD was conducted in North Gondar with Muslim religious leaders/fathers who were aged 45-65 years. All the six participants in this FGD confirmed the persistence of rapid population growth and its associated problems. They responded that the maximum number of births should be limited. Three of them approved three children while the other three were in favour of four children throughout the life of a couple. Most participants were not, however, comfortable on the passage of a law by the Government regarding the maximum number of children before the whole Muslim community of their area discusses it. On the other hand, they reported that they would accept the passage of a law if it is approved by the Federal Islamic Affairs Supreme Council. All of them were in favour of female children. Some statements put forward by each of the three participants are given below.

At the beginning when I had a male child I was very happy. But later on, I realized that my female children were more successful and useful. The male children are rather more destructive and burden of their parents. The old tradition was favouring a male child. This was happening with the assumption that a male child will be a supporter of his father at times of difficulty. However, this does not seem to hold true in most situations nowadays. I have both male and female children. If there were any possibility, I would change two of my male children with one female child of another family.

Further in-depth interviews were conducted with a Sheikh (South Gondar) who was aged 30 years, regarding limiting the number of children and the passage of a law by the Government. The Sheikh approved the passage of a law by the Government. 
He was in favour of four children, and the mechanism he proposed to bring the number of children to the required level was: restricting the number of sexual intercourses.

To investigate the conflicting opinions among the Muslim religious leaders, there appeared a necessity to carry out a key-informant interview with a scholar in the centre of the Amhara region-Bahir Dar. Accordingly, the discussion was made with an intellectual person who is knowledgeable of the Quran and a member of the Amhara Region Islamic Affairs Supreme Council. He was in favour of three or four children during the entire life of a couple. However, the scholar did not like to give a direct answer to the passage of a law regarding the maximum number of children that a couple should have at the end of the day. Instead, he stressed the importance of making the preferred methods available and accessible to the needy ones free of charge, along with necessary education and health services. If that is the case, he expressed his belief that each individual woman will not have more than four children. Finally, he said, "uncontrolled population growth could ignite and aggravate conflicts that may arise among several social groups having different and endless interests."

Key-informant interviews carried out with experts from the Education and Finance and Economic Development Bureaux

It was necessary to investigate the reasons why quite a large number of students at the primary level left school during the last academic year. The possible reasons given by the expert working at the Education Department of North Gondar zone were: early marriage (females), child labour, and lack of money for buying necessary materials. The next question raised was: what actions are you planning to take to reduce or stop the number of drop-outs? The expert suggested the expansion of the experiences of some schools and non-governmental organizations (NGOs) working in the area which are supporting students by providing them with food and other necessary materials.

Further interviews were conducted with experts from the Department of Population Affairs (Amhara National Regional State Bureau of Finance and Economic Development) regarding the organizational structure at different levels (region, zone, and woreda) and the activities carried out so far. It was learned from them that quite a substantial amount of population-related work is carried out by external assistance. On the other hand, the population of the Amhara region was reported to be increasing by some 500,000 every year. One of the experts said, "roughly, in half of the woredas of the region, experts are assigned. Assigning of such experts who are BSc degree-holders is taking place in the remaining woredas of the region. So far, only one expert is assigned in each zone or woreda to run population-related activities."

\section{DISCUSSION}

This study has shown the perception that the extent of disharmony between the natural resource base (mainly land) and the population to be sustained is getting wider and wider. The fundamental resource base of the rural population, i.e. land, is suffering from different forms of degradation, such as over-cultivation, erosion, fragmentation, etc. The emergence of a considerable number of rural people lacking farmland and the ever-decreasing average land-holding per person in the typical rural areas are indicative of the fact that the population pressure is reaching critical levels. This finding is in agreement with an earlier report that indicated the average land-holding per rural person as 0.21 hactare in 1999, down from 0.5 hactare in the $1960 \mathrm{~s}$ (16). The perceived incompatibility between the size of population and the available resources, including farmland, is manifested by, among other things, dramatic changes in the attitudes towards the maximum number of children that a couple should have in their lifetime. Most study subjects were in favour of four or less children. These findings of linkages between views on population and resource pressures and views on the size of the family are in agreement with the results of earlier studies conducted elsewhere in Ethiopia $(13,14,17)$. It was also learnt from the present study that the population of the two Gondar zones would double itself in about 26 years if the present growth rate of $2.7 \%$ persists. The total fertility rate of 5.3 obtained in the present study is compatible with the results of the 2005 EDHS which showed total fertility rates of 5.1 and 5.4 for the Amhara region and the entire country respectively (5).

Although there appears a sort of discrepancy between the earlier estimations and the recent census results about the size of population of Ethiopia, it could generally be said that the population of the country is still considerably very high.

Over $90 \%$ of the women who participated in the quantitative study and nearly all the focus-group discussants and interviewees felt that something should be done to keep the population from growing too fast. Such inclination among the overwhelming majority of the population demonstrates a tremendous shift from the old tradition of aspiring for a large family size. Throughout the course of the present study, it was learnt that most 
people with varying background characteristics are not encouraged to have a large family. The other attitudinal change is the growing tendency of most men and religious leaders towards the preference for a female child unlike the earlier traditions $(5,6)$. However, despite such attitudinal changes, the use of modern contraception as reported by the participants is generally low. In fact, the current use of modern family-planning methods, when compared with earlier reports, is encouraging. According to the 2005 EDHS report, the CPR among currently-married women aged 15-49 years in the Amhara region was $15.7 \%$ (5).

It is true that most findings obtained have clearly shown that the various social groups are well aware of the current population pressure. If the position of most people is to accept harsh but meaningful changes, it is also reasonable and logical to explore the activities of the responsible bodies and how they respond and address the unavoidable issue of population pressure in present Ethiopia.

Rapid population growth has been increasingly recognized as a proper area of public-policy interventions by many governments. The concern is not only with the ever-increasing demographic growth per se but also to its negative implications for the attainability of a wide range of desirable goals in the sphere of economic, political and social development. In this regard, the formulation of the Ethiopian Population Policy in 1993 was a breakthrough for a country with a high uncontrolled population growth but unfortunately was not able to reduce the forthcoming population pressure (12).

It is now about 15 years since Ethiopia has adopted the population policy which has got a number of goals, objectives, and strategies (12). The efforts made so far to tackle the problem of population pressure are encouraging. However, the implementation of the 1993 population policy is lagging behind, and it is likely that most Millennium Development Goals (MDGs) that are directly related to population issues may not be met $(17,18)$. Although some reports insist that Ethiopia is on track and will meet most MDG targets by 2015 (19), other scholars continue expressing their confidence that the MDGs (even those relating to maternal mortality) would be met if the current strategies followed by the country, i.e. accelerated expansion programmes, are achieved as planned with the anticipated levels of quality (20).

The reports obtained from the Department of Population Affairs indicate that population-related activities are carried out largely by the assistance of donors and NGOs. Given the present population pressure, it is high time for the regional government to establish an organizational structure together with the necessary human power and other resources that would effectively tackle the population problem. Based on the findings of the quantitative and qualitative studies, the following recommendations are put forward:

As rapid population growth in Ethiopia is becoming a serious problem, it would be advisable to organize a national conference in which religious leaders of the highest levels, scholars, ministers, representatives of NGOs, and other responsible bodies could participate. Similar conferences should also be carried out at the regional, zonal and woreda levels. In this regard, the experience of the Islamic Republic of Iran could be of high importance (21).

Further studies need to be undertaken in different parts of the country to investigate if similar attitudinal changes are emerging. Findings of these studies, including the present one, and ideas (suggestions) that may be collected from various conferences on population affairs could assist the Government whether passing a law limiting the number of children is worth considering.

Strengthening of the Department of Population Affairs to a level where it could fully function and achieve meaningful changes is vital. The minimum requirement from the regional government is to improve the organizational structure. In this regard, the current department needs to be upgraded to the level of a bureau which would be under the direct supervision of the regional government itself. The new bureau that may be established, the Bureau of Population Affairs would be instrumental in integrating all other population-related activities carried out by different stakeholders. This will ultimately play a pivotal role in the achievement of the common goal.

It was learnt from the present study that the use of contraception among women, particularly married women, was encouraging. However, the $\mathrm{CPR}$ among the rural women is still very low. Therefore, the family-planning programmes of the two zones should be strengthened to the extent that they could play significant roles in bringing down the prevailing high fertility in such areas where about $85 \%$ of the population lives. Accordingly, the main stakeholders should exert maximum efforts to make the method of contraception choice available and accessible to users. 


\section{ACKNOWLEDGEMENTS}

The authors thank all women, married men, religious leaders, experts of the Department of Population Affairs, and other individuals who generously committed their time in participating in the study. The authors thank the Amhara Region Health Bureau, North Gondar and South Gondar Zonal Health Offices for their assistance and permission to undertake the research. The authors are highly indebted to the respective Woreda Health Offices for their assistance in providing them with the necessary supporting letters to each rural and urban kebele administrations where actual data collection was carried out. Finally, the authors would like to acknowledge the School of Public Health (Medical Faculty) of the Addis Ababa University for its financial support.

\section{REFERENCES}

1. Population Action International. Africa at the turning point: development hinges on success in population, health. Washington, DC: Population Action International, 1998. 3 p.

2. United Nations Population Fund. State of the world population 2004: the Cairo consensus at ten: population, reproductive health and the global effort to end poverty. New York, NY: United Nations Population Fund, 2004. $124 \mathrm{p}$.

3. World Health Organization. Maternal mortality 2005: estimates developed by WHO, UNICEF, UNFPA and the World Bank. Geneva: United Nations Population Fund, 2007. $46 \mathrm{p}$.

4. United Nations. Department of Economics and Social Affairs. Statistics Division. Progress towards the Millennium Development Goals, 1990-2005. Millennium Development Goals indicators. New York, NY: Statistics Division, Department of Economics and Social Affairs, United Nations, 2005. 14 p. (http:// unstats.un.org/unsd/mi/goals_2005/goal_3.pdf, accessed on 1 January 2009).

5. Ethiopia. Central Statistical Agency. Ethiopia demographic and heath survey 2005. Addis Ababa: Central Statistical Agency, 2006:47-109, 231-3.

6. Fitaw Y, Berhane Y, Worku A. Differentials of fertility in rural Butajira. Ethiop. J Health Dev 2003;17:17-25.

7. Hailemariam A, Tesfaye M. Determinants of infant and early childhood mortality in a small urban community of Ethiopia: a hazard model analysis. Ethiop $J$ Health Dev 1997;11:189-200.

8. Assefa M, Drewett R, Tessema F. A birth cohort study in South-West Ethiopia to identify factors associated with infant mortality that are amenable for intervention. Ethiop J Health Dev 2000;14:161-8.

9. Brown University. Population Studies and Training Center. Proximate determinants of fertility in Amhara region, Ethiopia: an application of the Bongaarts model. Providence: Population Studies and Training Center, Brown University, 2003. 6 p. (Background report: partnership in improving reproductive health no. 8).

10. The David and Lucile Packard Foundation Population Program support in Ethiopia. In: Reproductive health/family planning and HIV/AIDS: knowledge, attitude, behaviour and services in three project focus zones in Amhara region, Ethiopia. Addis Ababa: Addis Ababa University, 2001:30-3.

11. Bongaarts J. A framework for analyzing the proximate determinants of fertility. Pop Dev Rev 1978;4:105-32.

12. Ethiopia. Office of the Prime Minister. National population policy of Ethiopia. Addis Ababa: Office of the Prime Minister, Government of Ethiopia, 1993. 59 p.

13. Regassa N. Socio-economic correlates of high fertility among low contraceptive communities of southern Ethiopia. J Hum Ecol 2007;21:203-13.

14. Ezra M. Demographic responses to environmental stress in the drought- and famine-prone areas of northern Ethiopia. Int J Popul Geogr 2001;7:259-79.

15. Ulin PR, Robinson ET, Tolley EE. Qualitative methods in public health: a field guide for applied research. San Francisco, CA: Jossey-Bass, 2005;139-69.

16. World Bank. Country Department for Ethiopia. Capturing the demographic bonus in Ethiopia: the role of gender equitable development and demographic actions. Addis Ababa: Country Department for Ethiopia, World Bank, 2006:1-2. (Report no. 36434-ET).

17. Teller $\mathrm{CH}$, Gebreselassie T, Hailemariam A. The lagging demographic and health transitions in rural Ethiopia: socioeconomic, agro-ecological and health service factors effecting fertility, mortality and nutrition trends. Fifth African Population Conference, Union of African Population Studies. Arusha, 10-14 December, 2007. 26 p. (http://uaps2007.princeton. edu/download.aspx?submissionId=70214, accessed on 2 January 2009).

18. United Kingdom. Department for International Development. Country profiles: Africa, Niger. London: Department for International Development, 2006. 25 p. (www.dfid.gov.uk/pubs/files/cap-ethiopia-draft. pdf, accessed on 2 January 2009).

19. Liungqvisit. UNICEF lauds Ethiopia's progress in attaining MDGs. Addis Ababa: Walta Information Center, 2008:1-3. (http://www.waltainfo.com/walnew/index.php?option=com_content\&task=view\&i $\mathrm{d}=2000 \&$ Itemid=46, accessed on 4 January 2009).

20. Girma S, Yohannes AG, Kitaw Y, Ye-Ebiyo Y, Seyoum A. Human resource development for health in Ethiopia: challenges of achieving the Millennium Development Goals. Ethiop J Health Dev 2007;21:216-31.

21. Hoodfar H, Assadpour S. The politics of population policy in the Islamic Republic of Iran. Stud Fam Plann 2000;31:19-34. 